\title{
Exploring the potential for collective leadership in a newly established hospital network
}

\author{
Aoife De Brún and Eilish McAuliffe \\ University College Dublin Centre for Research, \\ Education and Innovation in Health Systems (UCD IRIS), \\ School of Nursing, Midwifery and Health Systems, University College Dublin, \\ Dublin, Ireland
}

\begin{abstract}
Purpose - Achieving integrated care is a key focus for health systems and has resulted in various structures between and within organisations. The reorganisation of the Irish health system into hospital networks/groups aims to encourage work across hospitals to integrate care. This study evaluated if collective leadership emerged over time through increased interaction and collaboration following the organisation of hospitals into a network. A secondary aim was to elucidate the potential for collective leadership, through understanding the barriers and enablers perceived by participants.

Design/methodology/approach - This study employed social network analysis and qualitative interviews. Leaders across the hospital group were invited to participate in an online network survey and interviews (analysed using thematic analysis) at three time points over an 18-month period.

Findings - Although there was evidence that some parts of network were beginning to operate collectively, the structures observed were more typical of a hierarchical network. Disruption in the network and uncertainty regarding permanence of the organisational structure had a negative impact on the potential for collective leadership. Yet, progress was evident in terms of establishing building blocks for collective leadership and integration, including developing trust, mutual understanding and creating space for change.

Practical implications - This study contributes to the literature by reflecting on the mechanisms and initiatives perceived as enabling/inhibiting collective leadership. Based on this research, it is important to communicate a clear and consistent message about the plans for the organisations involved and be clear regarding the roles and expectations for those involved in introducing new approaches to leadership and integration. Honest collaboration, openness and certainty in communication will likely be important in order to help create the contextual conditions to enable collective and system approaches to introduce "stepping stones" to change. These conditions include developing interpersonal relationships between leaders, creating time and space for deep and shared reflection, and enhancing trust among colleagues.
\end{abstract}

Originality/value - A key strength of this study is the linking of leadership-as-networks theory with social network methods to investigate collective leadership in practice. This study contributes to the literature by reflecting on the mechanisms and initiatives perceived as enabling/inhibiting collective leadership.

Keywords Social network analysis, Leadership, Health, Systems, Collective leadership

Paper type Research paper

(C) Aoife De Brún and Eilish McAuliffe. Published by Emerald Publishing Limited. This article is published under the Creative Commons Attribution (CC BY 4.0) licence. Anyone may reproduce, distribute, translate and create derivative works of this article (for both commercial \& non-commercial purposes), subject to full attribution to the original publication and authors. The full terms of this licence may be seen at: http://creativecommons.org/licences/by/4.0/legalcode

This research is funded by the Irish Health Research Board, grant reference number RL-2015-1588. This research is also supported by the Health Service Executive. We would like to thank the participants for their involvement in this study.

Declaration of interest statement: Authors have no competing interests.

Collective leadership in hospital network

Received 15 August 2019 Revised 19 January 2020 Accepted 19 January 2020 
JHOM 34,4

\section{Introduction}

Organisational structures in healthcare can exert a powerful influence on healthcare delivery, efficiency of care, and have implications for the successful integration of healthcare services (World health organization, 2000). The structure and organisation of health systems will often prescribe organisational operations that best fit such systems. When a system is then restructured, this can have significant ramifications on healthcare services, care pathways, service integration, organisational trust, as well as leadership roles and responsibilities within the system (Laschinger et al., 2000; Best et al., 2012; Greenhalgh et al., 2009). The recent reconfiguration of the Irish health system into hospital groups provided the opportunity to explore leadership among senior managers and executives in a newly networked group of hospitals. Using social network and qualitative analysis, this study maps the interactions of leaders in this network to evaluate whether collective leadership emerges organically following system reconfiguration, as well as elucidating the potential for collective leadership by exploring the barriers and facilitators to enhanced collaboration and collective working in the network.

Recently there has been renewed interest in the integration of health systems, representing a move from silo-based systems and organisations to more integrated structures that aim to enhance access to services, effectively share resources, and improve the quality and experience of care (Porter and Lee, 2013). According to the World Health Organization (WHO), integrated service delivery can be defined as "the organization and management of health services so that people get the care they need, when they need it, in ways that are user-friendly, achieve the desired results and provide value for money" (World Health Organization, 2008). Yet, the challenges of effective interorganisational collaboration are manifold and include issues related to power and control, communication, and conflicting expectations (Keyton et al., 2008). Structural and governance changes that have segmented healthcare, heightening competition between provider organisations. Such competition can be a driver or enabler to integration in some organisations, but some organisations may have a history of competition or conflict that could inhibit or slow collaborative efforts (Al ramiah and Hewstone, 2013). Effective leadership is a pivotal factor in overcoming these barriers and achieving interorganisational collaboration and integration (Suter et al., 2009; West et al., 2015). In order for collaboration for collective action (a pre-requisite for integrated care) to be realised, it is necessary that there is a shift from compartmentalisation and siloed working to more inclusive and collaborative approaches to decision-making and problem solving (Kramer et al., 2018; The King's Fund, 2017).

\section{Theory}

Given the increased emphasis on interorganisational collaboration in healthcare, there have been concomitant calls for a more inclusive approach to healthcare leadership (Beirne, 2017; West et al., 2014). There is a growing interest in collective (or shared or distributed) leadership and its applicability to healthcare settings. A collective approach to leadership may be defined broadly as a dynamic process where leadership roles and responsibilities are shared among multiple team members (D'innocenzo et al., 2014), where individuals are empowered to lead the team where they have the motivation and expertise to do so, as required by the task or challenge facing the team (Friedrich et al., 2009). Thus, different people may lead the team at different times on different tasks, commensurate with expertise and experience. Evidence for the benefits of such approaches is emerging. Recent systematic reviews have found that, across sectors, collective and shared approaches to leadership are associated with improved team performance and team effectiveness (D’innocenzo et al., 2014; Wang et al., 2014; De brún et al., 2019).

Senge et al. describe collective leadership and system leadership as "two sides of the same coin" (2015, p. 33) and assert that system leaders are required to cultivate shared ways of 
working and to make the best use of collective knowledge and expertise. They highlight that in complex settings, people often focus their attention on parts of the systems that are visible and accessible to them, thus holding different perspectives on problems and possible solutions depending on their particular vantage point (Senge et al., 2015). Helping people to see and understand the wider system is essential to building a shared understanding of challenges and in turn, can foster collaboration and problem solving across organisations.

The term "heterarchy" has been employed as a contrast to "hierarchy" to conceptualise how dynamics around influence and power can change in response to situational demands (Aime et al., 2014; Sullivan et al., 2015). This is consistent with collective leadership, where an individual leads the team where they have expertise, skills and motivation as the task at hand requires (Friedrich et al., 2009). In contexts where strategic change occurs under conditions of ambiguity, the creation of a collective leadership group, where members play active and complementary roles, was found to be crucial in achieving change (Denis et al., 1996, 2001). This resonates with intergroup contact theory, which asserts that regular contact between actors of various groups or organisations provide an effective means by which to reduce, resolve and prevent conflict and promote effective collaboration (Al ramiah and Hewstone, 2013).

In line with this systems approach to leadership, researchers have advocated a shift away from studying individual leadership in a network or team and called for the conceptualisation of leadership as networks, where multiple individuals can adopt leadership roles (Carter and Dechurch, 2012; Carter et al., 2015). Networks have been described as "the fundamental way in which we can see and measure how collectives are engaging in leadership" (Cullen et al., 2014). Network approaches as a lens to explore leadership and, in particular collective leadership, recognise leadership as a social and relational process and emphasise that it is the structure of relationships that produce leadership outcomes. Social network analysis (SNA) is an approach that can facilitate empirical research on collective leadership and enable researchers to develop a holistic map of a network or system (Carter and Dechurch, 2012; Balkundi and Kilduff, 2006). SNA enables researchers to map, measure, and analyse social relationships between people, teams, and organisations (Borgatti et al., 2013). The patterning of ties among actors in a network provides opportunities and constraints to the access of resources, information sharing, and social support (Borgatti et al., 2009) and therefore such methods are "exceptionally well-suited" to the exploration of plural approaches to leadership (Carter et al., 2015).

Mayo et al. (2003) were among the first to apply the method to collective leadership evaluation. In their work, they focused on centralization and density as two valuable network metrics to assess and map collective leadership. Density explores the number of actual ties observed in the network as a function of the number of possible ties, whereas network centralization explores the degree to which the network is focused on one or a few individuals. When collective leadership networks effectively empower members, they can grow as a large network of clusters (Hoppe and Reinelt, 2010). Moreover, the network becomes more efficient when these clusters are connected or bridged by individuals high in "betweenness" (the frequency a person lies on the shortest path connecting everyone else in the network). Individuals high in betweenness are said to occupy a strategic position in a network. Whilst network metrics such as density, centralization, and betweenness are useful in providing insights into organisational structure, researchers have also recommended combining network measures to understand certain network types. Specifically, Mayo et al. (2003) contend that the highest levels of collective leadership would result in both high network density and low network centralisation.

This study explored how the re-configuration of hospitals into a networked structure impacted upon interaction among actors in the network with the aim of determining whether collective leadership was emerging over time in the network. The following research questions (RQs) were addressed: 
JHOM 34,4
$R Q 1$. Is there evidence that collective leadership is emerging through increased interaction and collaboration following the organisation of hospitals into a networked structure?

$R Q 2$. What are the barriers and enablers to enhanced collaboration and collective leadership?

\section{Methods}

Context of the research

The Irish healthcare system has undergone considerable change and reorganisation in recent decades, often with little or no measurement of the impact of change on leadership, healthcare delivery or patient safety (Mcauliffe, 2014). The most recent reorganisation of the Irish healthcare system was prompted by changing healthcare demands in line with those observed internationally: demographic changes, technological advancements, public expectations, and financial pressures on services. In order to address these issues, it was recommended that hospital groups were established in Ireland (Higgins, 2013). The rationale for this structural change was that the formation of hospitals into a small number of groups would provide the optimal configuration to enable hospitals to deliver high quality, safe and cost-effective care, and to better support integration of services across hospital sites and community services (Higgins, 2013). It was intended that each hospital group would have its own governance and management structure as appropriate to the geographic region and patient population. The hospital groups were initially established on an administrative basis with the plan that this would be evaluated before the formal establishment of independent hospital trusts.

Previous healthcare organisational structures in Ireland were described as restricting the development of the management systems and leadership required to run a world-class national hospital network (Department of health, 2012). The increased autonomy of the groups was considered necessary to promote appropriate accountability, to enable more effective leadership and leadership capability, to promote the successful integration of services and to maximize efficiency of care delivery through the groups operating as single cohesive entities. However, the legislation underpinning this new configuration has been enacted. At time this of this research, the hospital groups were operating without formal legislative authority and still working under the purview of, and reporting to, the national healthcare organisation.

There were seven hospital groups established and one of these groups was the focus of the current study. This hospital group includes eleven hospitals; six are voluntary and five are statutory hospitals. These two hospital types had different funding and governance structures resulting in very different degrees of autonomy and considerable differences in culture and leadership. The lack of legislation underpinning the restructuring caused challenges in terms of creating a formal network. This research was conducted at the early stages of the establishment of the network, that is, when it was still operating without a legislative basis, with the expectation that the network structure would be formalised in the coming months. In expectation that this legislation was imminent, the 11 hospitals were expected to operate as a single network to advance the shared goals of the group. It was intended that senior leaders would coordinate and collaborate across sites to enable integration and streamlining of services to improve care delivery within a bounded geographic region. A range of working groups and speciality-specific collaboratives were established to align with a transformation programme across the group. The hospital group employs more than 10,000 people and services a population of 1.1 million.

Ethical approval for the study was granted from University College Dublin Research Ethics Committee (ref: HREC-LS-16-116 397/LS-16-20) and participants provided their informed consent. 


\section{Social network analysis}

To map the relations between network members this research explored both network-level and node-level metrics. Network metrics are those that provide information about the network, whereas node-level metrics provide information about individuals in the network. Network-level metrics of interest included network density and network centralization. Nodelevel metrics relevant to this research and reported here include betweenness centrality, reciprocity and in-degree. Betweenness centrality measures the frequency a person lies on the shortest path connecting everyone else in the network. In-degree measures the number of links to a person in the network and reciprocity indicates that relationships are perceived similarly by individuals.

Alongside the network and node metrics, we also conducted qualitative interviews at each time point. The rationale for this approach was to elucidate what was working well in the network and to identify the potential for collective leadership in the network. Additionally, we sought to explore the barriers to enhanced collective working. Qualitative data also aided with the interpretation of network maps.

\section{Participant identification and recruitment}

Participants were eligible to take part in the study if they were in the role of Chief Executive Officer (or General Manager), Director of Nursing, or Clinical/Medical Director in one of the 11 hospitals. These positions $(n=33)$ were selected for inclusion in the study as these were common positions across all 11 organisations and each of the professional groups had recently established regular meetings to bring together people in the same role across hospital sites. The executive management team of the hospital group ("hospital group management team", $n=10$ ), which had the role of supporting and enabling the operation of the network, were also eligible and invited to take part in the study. In total, 43 individuals formed the initial cohort for this work.

Prospective participants were invited to register their consent to participate in the study via a sign-up web page. The information sheet and a letter of invitation from the Chief Executive Officer of the hospital group on behalf of the research team was forwarded to those eligible. These materials explained the purpose and aims of the research, emphasised the voluntary nature of participation and advised that participants would be asked to complete the survey at three time points over the study period. Participants were advised to note their interactions and collaborations with others in the network on their calendars to help ensure accurate completion of the network survey.

\section{Data collection}

Participants in the study all occupied formal leadership roles in the network. Therefore, rather than asking them specifically about leadership, we asked about their behaviour as leaders in the network to assess if they were enacting collective leadership in practice. Our questions were centred around the building blocks required for the emergence of collective leadership (Senge et al., 2015) and thus, we asked participants to report their activity and frequency of contact and collaboration (e.g. cross-site initiatives, goals, tasks, etc.) with other network members. Researchers have advocated the use of alternative approaches to mapping leadership, such as tracing evidence of interactions by recording and exploring email interactions or observation of meetings (Carter and Dechurch, 2012). We employed this approach to understand if the levels of contact and collaboration across the group indicated whether there was potential for the future emergence of collective leadership. Likert-type scales were used to determine the type and strength of directed links between individuals at snapshots of time (e.g. "During the past month, how frequently did you contact your colleagues listed below (during work time) [1]?)", where 1 represented no contact or

\author{
Collective \\ leadership in \\ hospital \\ network
}


JHOM 34,4

collaboration and 5 represented daily contact or collaboration. The roster method was used for these network questions, where respondents were asked to cite their frequency of contact and collaboration with all other individuals listed as part of the network. This approach ensured that weak ties as well as strong ties are measured, and that there was no ambiguity about the boundaries of the network (Valente, 2010). The online survey was hosted by Qualtrics (www.qualtrics.com).

The evaluation of collective leadership in a network presents challenges in that collective networks tend to be dynamic and ties and relationships may be fluid, adapting to issues and priorities as they occur. Thus, we anticipated that mapping the network at three time points would facilitate understanding of the dynamic nature of the network and of leaders' interactions in the network. Data collection occurred a three time points over an 18-month period. Two email reminders were issued to non-responding participants at weekly intervals at each time point. At each round of data collection, the survey was live for three weeks.

Using purposive sampling across hospitals and role types, a subset of participants was also invited to take part in an in-depth semi-structured interview at each point. The interview guide addressed a range of topics including asking about those with whom participants worked with most closely in their role (both within and across sites), whom they sought for collaboration and advice and why they sought out these individuals. We also gathered perspectives and experiences of working within the newly established network, explored participants' perceptions of the functioning of the network (what was working well or not working so well), queried what they believed was the greatest potential and the biggest risk posed to the network, as well as their expectations for the network moving forward. Of those invited, 13 agreed to take part over the study period.

\section{Data analysis}

Network survey data was analysed using descriptive statistics and entered into UCINET and Netdraw to generate network maps and to compute relevant network and node-level metrics.

One-on-one interviews were audio-recorded, and the data were managed using NVivo11. The first author has extensive experience in interviewing and qualitative analysis and conducted all interviews. Thematic analysis, a method to identify, analyse, and report patterns within a data set, was employed to analyse the data (Braun and Clarke, 2006). Drawing on the approach outlined by Braun and Clarke (2006), the first step of analysis compels the researcher to immerse themselves in their data by repeated readings of texts to familiarise themselves with the content. All transcripts were read, and initial codes generated and recorded by the first author. These codes represented the most basic element of the data that can be assessed in a meaningful way and helped to organise and group the data. After initial coding, codes were collated, collapsed, or refined to identify broad patterns in the data. These initial themes and their process of development were then presented in detail to the second author. Through discussion, key themes and findings were confirmed and finalised.

\section{Results \\ Sample and response rate}

Table 1 displays information regarding the sample at each time point. The response rates were $80 \%, 63 \%$ and $53 \%$ at each respective time point. Prior to data collection at T2, the hospital group recruited additional staff, expanding the network significantly. Across all time points, a total of 66 individuals were eligible to take part but 17 of these did not take part in any phase of the research. Of these 17 who did not participate, four left their role (and the network) during the study period and 10 were added to the network after T1. Fourteen individuals took part in an interview over the study period $(T 1=5 ; T 2=3 ; T 3=6)$. 


\begin{tabular}{|c|c|c|c|c|}
\hline & $\begin{array}{c}\text { Number eligible to } \\
\text { participate }\end{array}$ & $\begin{array}{l}\text { Number of participants } \\
\text { (response rate) }\end{array}$ & Non-responders to survey & $\begin{array}{l}\text { Collective } \\
\text { leadership in }\end{array}$ \\
\hline Time 1 & 42 & $34(80 \%)$ & $\begin{array}{l}4 \text { Clinical directors, } 1 \text { Chief executive officer/ } \\
\text { General manager (CEO/GM), } 1 \text { Director of nursing } \\
\text { and } 2 \text { group management team members }\end{array}$ & networ \\
\hline Time 2 & 54 & $34(63 \%)$ & \multirow{2}{*}{$\begin{array}{l}\text { nursing and } 6 \text { group management team members } \\
7 \text { Clinical directors, } 6 \mathrm{CEOs} / \mathrm{GMs}, 2 \text { Directors of } \\
\text { nursing and } 11 \text { group management team members }\end{array}$} & 4 \\
\hline Time 3 & 55 & $29(53 \%)$ & & \\
\hline $\begin{array}{l}\text { Note }(\mathbf{s}) \\
\text { program }\end{array}$ & $\begin{array}{l}\text { Prior to T2, the hosp } \\
\text { me for the group }\end{array}$ & group management tea & n expanded with the introduction of a transformation & $\begin{array}{l}\text { Sample and respo } \\
\text { rates across time po }\end{array}$ \\
\hline
\end{tabular}

Interviewees included 4 CEOs/GMs, 2 Clinical Directors, 5 Directors of Nursing and 3 members of the hospital group management team.

$R Q 1$. Is there evidence that collective leadership is emerging through increased interaction and collaboration following the organisation of hospitals into a networked structure?

Figures 1 and 2 display the network maps for contact and collaboration across the time points. Table 2 displays the relevant network-level metrics to evaluate whether collective leadership is evident, and Table 3 includes the node-level metrics.

Contact in the network Over the three time points, the network experienced considerable growth and turnover and consequently, the density of contact relationships decreased from $31 \%$ at $\mathrm{T} 1$ to $22 \%$ at T3. Despite this, participants report a consistent average of $12-13$ contact relationships in the network. In terms of contact reciprocity of ties in the network (ties perceived similarly), at T1 reciprocity was comparatively high at $50 \%$ but reduced to $24 \%$ and $27 \%$, respectively, at subsequent time points. We observed that within-site contact was most frequent, with frequent contact between the CEO group and the Directors of Nursing group across site. This latter finding is likely due to the fact that these groups were meeting regularly to advance their agendas and these meetings were well attended by these professional groups.

One of principal indicators of whether collective leadership has emerged in a network is centralization. In the current study, centralization scores were relatively high for contact relationships (average 0.71) indicating a centralized network. Those with the highest indegree were members of the hospital group management team and these individuals can be considered influential in terms of being contacted most in the network. This is more consistent with a hierarchical network structure and not with a network that is indicative of collective leadership.

Those high in betweenness centrality are said to occupy a strategic position in the network, as they lie on the shortest path connecting many others in the network. In the current study, three members of the hospital group management team (MG1, MG4 and MG2) were among the highest in betweenness centrality across all time points, though there was some evidence of this shifting over time, most likely in line with priorities and activities of the group at various time points. Given that those individuals highest in betweenness were members of the hospital group management team, this confirms again that the group management team are driving the contact in the preliminary stages of network development.

Collaboration in the network Given the network disruption observed during the study period, it is not surprising that a similar decrease in density of collaborative relationships was also observed $(T 1=29 \% ; T 2=19 \% ; T 3=18 \%)$. In terms of reciprocity of ties in the 
JHOM
34,4

456

Figure 1.

Frequency of contact across entire network over time (Time 1 [top], Time 2 [centre], Time 3 [bottom]
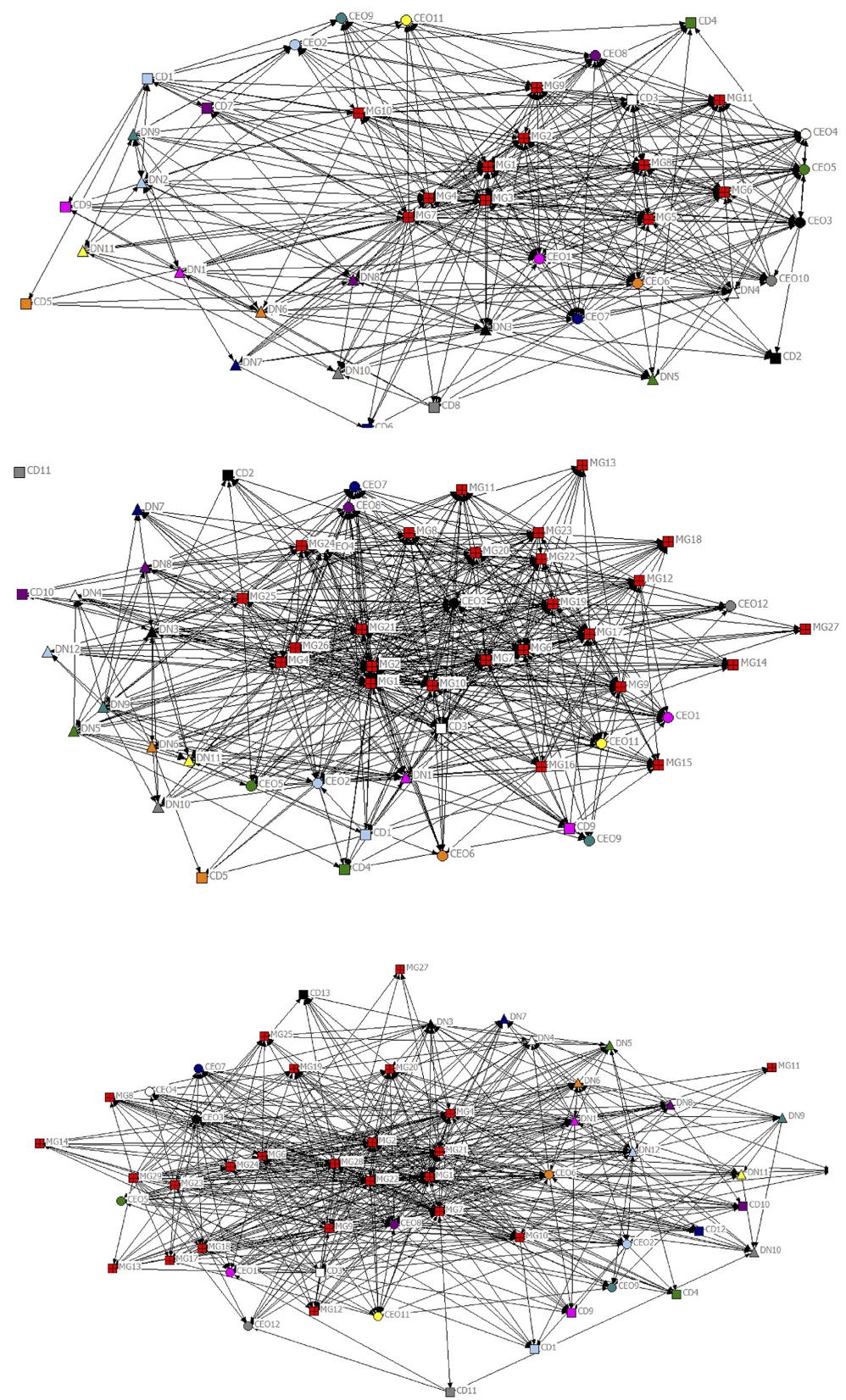

Note(s): Colours denote various organizations and red indicates members of the hospital group management team. Circles represent hospital CEOs, squares represent Clinical directors and triangles indicate Directors of Nursing 

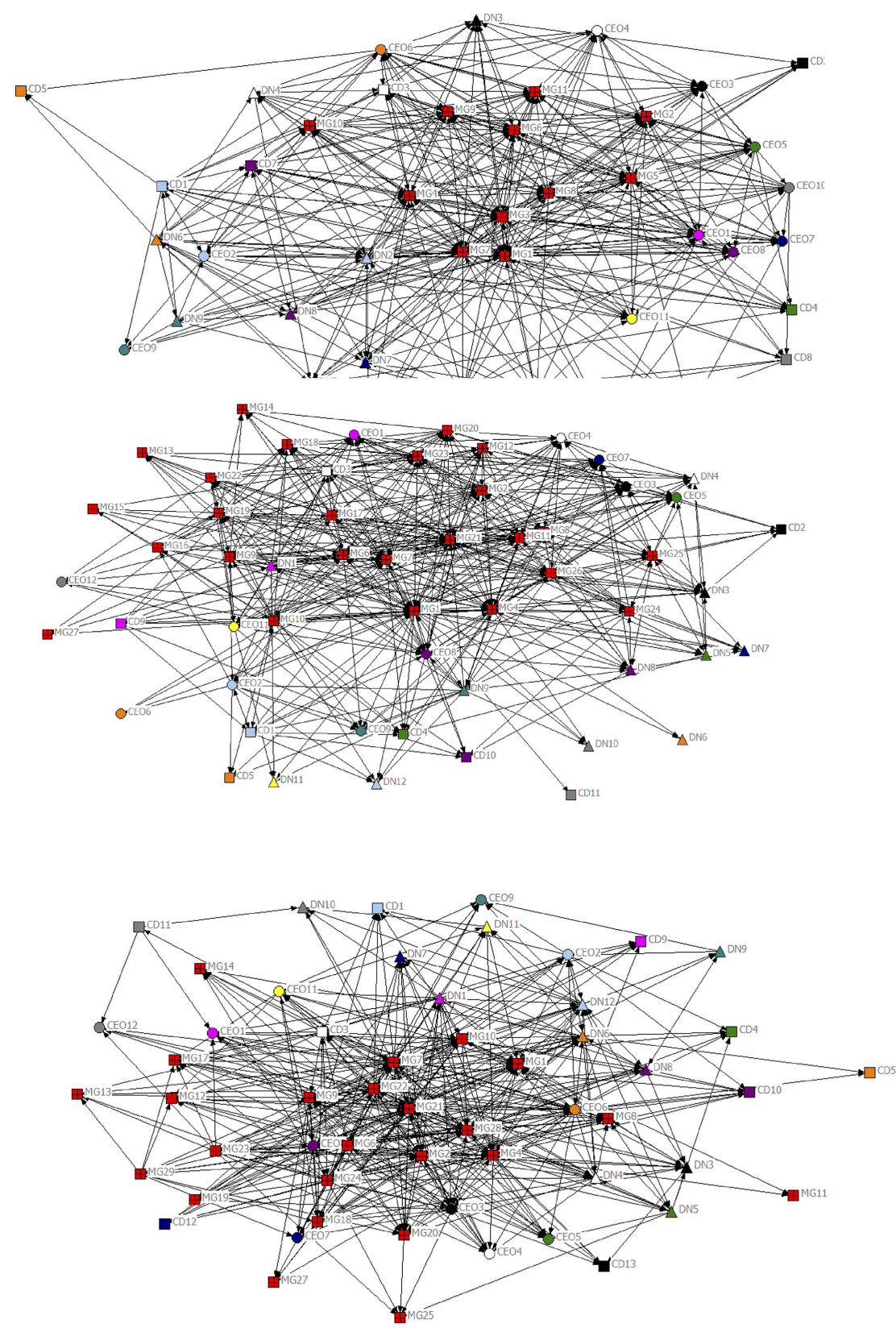

Note(s): Colours denote various organizations and red indicates members of the hospital group management team. Circles represent hospital CEOs, squares represent Clinical directors and triangles indicate Directors of Nursing
Collective leadership in hospital network

Figure 2.

Frequency of collaboration across entire network over time ((Time 1 [top], Time 2 [centre], Time 3 [bottom] 


\begin{tabular}{|c|c|c|c|c|c|}
\hline JHOM & & Time 1 & Time 2 & Time 3 & Change \\
\hline 458 & $\begin{array}{l}\text { Contact } \\
\text { Density } \\
\text { Av. links per person } \\
\text { Centralisation } \\
\text { Average distance } \\
\text { Diameter (SD) } \\
\text { Dyad reciprocity }\end{array}$ & $\begin{array}{c}0.31 \\
12.7 \\
0.67 \\
1.66(0.5) \\
3 \\
0.5\end{array}$ & $\begin{array}{c}0.24 \\
12.9 \\
0.77 \\
1.59(0.5) \\
3 \\
0.24\end{array}$ & $\begin{array}{c}0.22 \\
12.3 \\
0.69 \\
1.6 \\
4 \\
0.27\end{array}$ & $\begin{array}{c}-0.09 \\
-0.4 \\
+0.02 \\
-0.06 \\
+1 \\
-0.23\end{array}$ \\
\hline $\begin{array}{l}\text { Table } 2 \text {. } \\
\text { Network-level metrics } \\
\text { for contact and } \\
\text { collaboration across } \\
\text { entire network }\end{array}$ & $\begin{array}{l}\text { Collaboration } \\
\text { Density } \\
\text { Av. links per person } \\
\text { Centralisation } \\
\text { Average distance } \\
\text { Diameter } \\
\text { Dyad reciprocity }\end{array}$ & $\begin{array}{c}0.29 \\
11.74 \\
0.7 \\
1.75(0.6) \\
4 \\
0.39\end{array}$ & $\begin{array}{c}0.19 \\
10.29 \\
0.84 \\
1.69(0.5) \\
3 \\
0.3\end{array}$ & $\begin{array}{c}0.18 \\
9.68 \\
0.67 \\
1.69(0.6) \\
3 \\
0.23\end{array}$ & $\begin{array}{c}-0.11 \\
-2.06 \\
-0.03 \\
-0.06 \\
-1 \\
-0.16\end{array}$ \\
\hline
\end{tabular}

\begin{tabular}{llcc}
\hline & Time 1 & Time 2 & Time 3 \\
\hline Contact & & & \\
Highest in-degree [Person (result)] & MG1 (28) & MG2 (29) & MG4 (24) \\
& MG4 (27) & MG1 (26) & MG1, MG7 (21) \\
& MG6 (20) & MG5, MG6 (25) & MG2, MG20 (19) \\
Highest in Betweenness [Person (result)] & MG4 (192) & MG1 (191) & MG4 (142) \\
& MG1 (145) & MG2 (178) & MG7 (134) \\
& MG7 (95) & MG7 (75) & MG1 (113) \\
Collaboration & & & \\
Highest in-degree [Person (result)] & MG1 (26) & MG2 (30) & MG1 (23) \\
& MG4 (24) & MG1, MG4 (28) & MG4 (22) \\
& MG3, MG6 (23) & MG6 (25) & MG7 (20) \\
Highest in Betweenness [Person (result)] & MG1 (204) & MG1 (319) & MG7 (205) \\
& MG7 (140) & DN11 (167) & MG21 (142) \\
& MG3 (129) & MG5 (136) & MG4 (124) \\
\hline
\end{tabular}

Table 3.

Node-level metrics for contact and collaboration across network

network, at T1 reciprocity was highest at $39 \%$ but reduced to $30 \%$ and $23 \%$, respectively, at subsequent time points.

Centralization across the three time points was quite high (average 0.73 ), and notably at its highest after network expansion $(T 2=84 \%)$. This suggests that collaborative relationships may have been adversely affected by network changes and became more focused on certain individuals in the network. However, this centralization had reduced at T3 suggesting more collaboration driven from outside the group management team. The qualitative findings suggest that individuals felt it took time for them to learn how they could best work with other individuals and organisations in the network and this may explain the more recent shift toward decentralization. We again observed that within-site collaboration was most frequent, but again there was considerable cross-site collaboration evident among the CEO group and Directors of Nursing group. However, given the high centralization metric observed, the collaboration network is not indicative of collective leadership emerging.

Consistent with the low density of ties observed, it was evident that the average number of collaborative relationships reported decreased over time, from an average of 11.7 at $T 1$ to 9.7 
at T3. Again, those with highest in-degree (i.e. those that people reported collaborating with most in the network) were members of the group management team, though were not always the same individuals that were contacted most. Those highest in betweenness centrality also tended to be members of the management team, though there was a greater variation in those highest in betweenness across the time points, with one Director of Nursing among the highest in betweenness centrality at $T 2$.

RQ2. What are the barriers and enablers to enhanced collaboration and collective leadership?

The qualitative interviews conducted alongside the network survey at each time point were crucial in illuminating what was working well (and why) and the data identified the perceived barriers and enablers to collective working among leaders in the network, highlighting the potential for the emergence of collective leadership.

Barriers System reconfiguration fatigue was widely reported. There was a sense that the speed of organisational change and restructuring meant participants did not have the opportunity to fully settle into roles and effectively engage before further systems change. This also led to uncertainty regarding future change and a wariness about engaging fully with the new network configuration, lest the hospital group structure be dismantled in favour of a new configuration. If this were to occur, participants felt there was a risk of disregarding the considerable progress that had been made in building relationships and collaborations thus far.

One of the major barriers reported by participants was the lack of legislation underpinning the hospital group structure. Network members reported reluctance and uncertainty about fully engaging due to this. While legislation was intended to support increased autonomy of the groups, this had not yet materialised and instead there was a perception that group members were working on a "good will" basis (DN4, CEO11) in advance of the legislation conferring them with the autonomy required to operate effectively.

The lack of development of legislation means that the groups are really operating at this point in time without any governance structure to support their activity and that is becoming more of an issue as time goes on (CEO1).

Despite this challenge, there was a pervasive sense of involvement across the hospital sites, which was suggested to have increased over time. According to one participant "[the hospital group] has won over" (CEO11) staff and is working to minimise the impact of the lack of legislation through ensuring involvement, openness and enabling collaborative ways of working.

Another barrier that was often mentioned at time points 1 and 2 , was the fear among some hospitals regarding the loss of their individual identity and autonomy. This related to the potential impact of membership of the hospital group on service provision, staffing levels and organisation finances. In some instances, there was a lack of clarity around the future vision for individual hospital sites and that resulted in defensiveness and caution from hospitals when engaging with the group.

There could be more clarity about where they [the hospital group management team] see us in a years' time, in 2 years' time (DN8).

Another barrier to collaboration was the request to work through the hospital group management structure in some instances. Participants had been advised that activity should be channelled through the hospital group management team and while the management team were perceived as effective and supportive, there was a sense among a minority that this process could delay action in some instances.

\section{Collective leadership in hospital network}


JHOM 34,4

We've been trying to work more through the group structure rather than with the hospital, as instructed ... we had some quick wins when we were working directly, em, activity has stalled I think at this point in time (CEO1).

Although the expansion of the hospital group management team was considered necessary to deliver change and improvement, this alongside the turnover experienced in the early stages of the group structure was perceived as impeding the development of working relationships and in some instances, inhibited progress and reduced transparency and role clarity. There was recognition of a period of "adaptation" (CEO3) and rebuilding momentum after these changes.

Enablers One of the principal enablers of collaboration and integration reported was the regular face-to-face meetings introduced to build relationships and collaborations between network members. These were deemed crucial by for relationship building, for developing a shared understanding of each other's challenges and expectations, and to understand how they could effectively collaborate. The following quote is indicative of a more collective and systems mindset emerging, where in the past, the focus was acknowledged as very organisation centric.

It's a very good forum for finding out what's happening elsewhere it's a good forum for ideas in terms of what we could be doing so for all those things and I suppose in terms of how we can go forward as a group as well it is a good way, instead of looking at ourselves as individuals (DN4).

A history of working together or having networks beyond the hospital group were powerful enablers of collaboration within the network and helped to drive connections across organisations. Nearly all individuals reported having at least some working relationships that existed prior to the establishment of the hospital group and all interviewees reported they felt they could contact their peers in other sites or in the hospital groups management team when needed. Participants reported that they "would not hesitate" (DN8) to contact others when necessary. Network members were more inclined to rely on those in similar sized organisations or in organisations facing similar challenges for support and leadership. This demonstrates the potential for collective leadership when network members are experiencing similar issues across sites.

So, we're quite similar and we kind of - well, if I was struggling, I'd pick up the phone to [hospital name] to bounce something off her. Or actually, [name] at [second hospital name]. So I would kind of use them before I'd use the others if you know what I mean. (DN11)

Within the new structure, an enabler of collaboration was the perception that members had a voice and influence in network strategy and felt valued for their experience and expertise. Participants reported themselves and their staff as demonstrating greater engagement and "feeling part of the solution" (CEO3) where they did not previously. The opportunity to be involved in strategy working groups was considered positive and a way to further build collaborations and increase transparency around decision-making. However, involvement in such groups was sometimes seen as driven by a need to "protect you own patch" (CEO8).

Our opinion and the consequence of decisions that are made on the quality of care provided with a much more taken into consideration now I feel that would have been before. (DN4)

Performance reviews for hospital sites were described as data-driven, with "more emphasis now on patient safety and quality outcomes" (CEO1) than there had been in previous structures. Many reported that this transparent approach better enabled problem solving and more effectively targeted improvement efforts. It was also said to have made the objectives of the group more explicit, with greater clarity among leaders about their shared goals and objectives. However, this shift in focus also presented challenges. Participants reported feeling overwhelmed by increased reporting demands and by a degree of 
repetition in reporting. Due to the lack of legislation underpinning the group structure, hospitals were still under the purview of the national health organisation and also reporting to that structure. There were also concerns expressed by some around being open with data, and the impact this might have on the perception of the organisation. This sometimes led to the "appearance" of engagement but delays in truly engaging and sharing performance data.

The visibility, openness and transparency and emphasis on collaboration by the hospital group management team was valued by participants. The hospital group management team were often described as accessible and "approachable" (CEO1) and this close link was considered beneficial for accessing support and to enable quick decision-making. The sharing of training and resources across sites and the introduction of new dual-hospital appointments was also viewed as an enabler by participants. At time point 3, there was an increased sense that people were independently forging and building working relationships, where initially this was largely driven by, and facilitated through, the hospital group management team. This was considered a product of the structures and supports, such as the regular meetings, that had been enabled by the group management.

\section{Discussion}

This study examined the frequency of contact and collaboration between senior leaders in a newly established hospital group to explore the potential for the emergence of collective leadership following hospitals being placed into a networked structure. The qualitative component aimed to elucidate the barriers and enablers to enhanced collaboration and collective leadership to identify the potential for collective leadership. The study was conducted over 18 months, a period where the network experienced considerable change, disruption and growth. Based on previous research (Mehra et al., 2006; Mayo et al., 2003), a decentralized and high-density network is said to represent shared or collective leadership practices, but this was not evident in the current study. Instead, the network structures observed through measurement of interaction were more characteristic of hierarchical networks (West et al., 1999). Both the network and qualitative data support the finding that contact and collaboration is primarily being driven by and through the hospital group management team. However, there was evidence that some pockets within the network were beginning to operate effectively together. Qualitative data highlighted the perceived benefits of being part of the network and illuminated the barriers and enablers to greater crossnetwork collective action.

Traditionally, healthcare organisations are hierarchical in nature. While research suggests hierarchies may be beneficial in some contexts, there is increasing evidence for the value of collective approaches to leadership in healthcare (De brún et al., 2019). Small groups of organisations engaging in collective action may be considered strategic networks, where there is sharing of resources and joint plans and action and purposive collaboration and cooperation of actors over time (Knight, 2002). The healthcare organisations in this study have, for the most part, operated as individual entities. With the reorganisation of the health system into hospital groups, hospital sites are now asked to move towards collaboration and the integration of services. Given the network of study is still in its infancy, the network members are in the preliminary stages of learning how they can effectively collaborate across organisational boundaries. In previous research exploring collective action for implementation, it was asserted that an alignment between more formal hierarchical leadership and shared leadership functions can facilitate integration between organisational boundaries, with distributed leadership approaches as being the "oil that helps lubricate the systems" in achieving positive impacts and outcomes (Rycroft-Malone et al., 2016, p. 13). 
JHOM 34,4

One major barrier to working collectively experienced by participants was the lack of legislation underpinning the group. Power shifts to enable more collective leadership approaches need to be perceived by others as legitimate to be accepted and the perceived illegitimacy of power can effect impact (Aime et al., 2014). The delays in formalising the new health system structures and giving the hospital group the autonomy to function as an independent entity have resulted in some failing to fully engage and a concern that further systems change may be imminent. Given the frequency of change in the Irish health care service in recent decades (Mcauliffe, 2014), it is perhaps not surprising that there was caution and scepticism among network members against this backdrop of uncertainty. Without legislation in place, participants viewed actors as operating on a good will basis, as the management team did not yet have the statutory power to enforce new ways of operating.

The degree of disruption observed in the current study, alongside the uncertainty concerning the future of the hospital group structure, has likely constrained the opportunity for collective leadership to emerge. Under conditions of ambiguity, major substantive change is more likely to occur under unified collective leadership (Denis et al., 2001). Yet, system leaders may calculate that the investment of time and effort in building collaborations "is worth making only if there is reasonable certainty that those they are collaborating with are likely to be ongoing partners in transforming the systems for which they are jointly responsible" (The King's Fund, 2017).

In this study, we observed that contact and collaboration was high among individuals within their own organisation, but less frequent across organizations. One of the challenges of structural reorganisation is that individuals tend to identify foremost with their primary organisation, prompting them to engage in a social categorisation process, perceiving similar in-groups as within the organisation and out-groups as those beyond the local site (Haslam et al., 1996; Tajfel and Turner, 2004). This presents challenges to operating collectively as system leaders, as geographic and organisational separation can inhibit the development of shared leadership (Sullivan et al., 2015).

Deep and shared reflection has been described as a "critical step" in enabling people from different organisations to understand other perspectives (Senge et al., 2015, p. 28). Furthermore, Allport's (1954) contact hypothesis suggested that in order to reduce conflict, participants should be enabled to interact where they have equal status and influence, and should seek to promote common goals and encourage cooperation. Thus, in developing interorganisational collaboration, it is crucial to bring people together to recognise their mutual similarities and challenges, understand various perspectives and develop shared understandings of common issues and agree shared goals. It is evident from the current research that participants valued regular meetings with peers beyond their own organisation. These fora enabled members to learn how they could work together and develop realistic expectations for how they might effectively collaborate, given the demands on their respective services, and allowed time and space to build mutual understanding and to develop trust. Trust between parties is central to the effective operation of interorganisational networks (Newell and Swan, 2000). Trust is multi-dimensional concept and relates to dealing with risk and uncertainty and accepting vulnerability (Newell and Swan, 2000). Creating and sustaining strong interpersonal relationships is crucial to build trust to effectively share knowledge and resources and trust fostered through interpersonal relationships can, in turn, become "engrained in organisational routines, norms and values" (Dodgson, 1993).

An undertaking described as characteristic of system leaders is a focus on reorienting strategy and creating the space for change and allowing collective wisdom to emerge (Senge et al., 2015). Researchers advocate for the more deliberate and explicit alignment of those involved to ensure shared values, goals and a shared vision about the nature of 
collaboration (Rycroft-Malone et al., 2016; Jagosh et al., 2012; Kramer et al., 2018). The current findings indicate that a history of working together was a catalyst to collaboration. Learning how people can collaborate across organisational boundaries has been described as particularly important for those individuals and organisations without a shared history of working together (Olson et al., 2011; The King's Fund, 2017). This is evident in the current study in the establishment of working groups to bring together stakeholders from various organisations and from various perspectives and levels in the system to consider current processes and ways of working. Despite the uncertainty evident in the context of this study, there was widespread engagement across sites in the hospital group, positive expectations about the aims and goals of the group, and an enhanced sense of involvement in strategy and decision-making. Creating such conditions is crucial to bring about new ways of working at the systems level and to cocreating collective solutions to complex shared problems and reduce the sense of "being done to" (Senge et al., 2015; The King's Fund, 2017).

Effective leadership requires the management of relationships "where social ties are formed and maintained, initiatives are launched or avoided, and through these interactions, the work of the leader is accomplished" (Balkundi and Kilduff, 2006, p. 434). A key strength of this study is the linking of leadership-as-networks theory with social network methods to investigate collective leadership in practice. There is a dearth of empirical work conducted that attempts to match methods to collective leadership theory, but network approaches offer a valuable lens through which to explore collective and shared forms of leadership. Network methods more appropriately view leadership processes as a series of "influence relationships", where the patterning of relationships offers insight into leadership enactment in a network (Carter and Dechurch, 2012; Carter et al., 2015).

Researchers have advocated the use of alternative approaches to mapping leadership, such as tracing evidence of interactions by recording and exploring email interactions or observation of meetings (Carter and Dechurch, 2012). This study prompted leaders to note their interactions with others in the network for the purpose of reporting on the frequency of their contact and collaboration with other network members. Thus, we have explored leaders' interactions as a means of assessing whether collective approaches to leadership emerged through individuals being placed in this networked structure. We contend that novel and innovative methods are required to explore collective leadership and simply asking about who someone relies on for leadership, especially among already established senior leaders, may not be sufficient to understand the emergence of collective leadership. However, by understanding the interactions and mapping the collaborations between network members, one can obtain greater insight into the emergence of leadership, and how the leadership roles may change over time as the network adapts and reacts to novel issues and challenges.

In their perception of networks, people are described as "cognitive misers" who may hold a simplified perception of the network and perceive it as dominated by only a few individuals (Krackhardt and Kilduff, 1999). Social network analysis offers a valuable insight into a network as an accurate perception of the ties present can be a beneficial to highlight areas of strength and areas of opportunity or vulnerability in a network (Balkundi and Kilduff, 2006). Social network analysis may be considered a tool for seeing the larger system and mapping relationships among leaders and to enable insight into how relationships translate into leadership network structures. There is a dearth of empirical work conducted on leadership and social networks (Brass et al., 2004) and on exploring leadership as networks (Carter and Dechurch, 2012) and this research has contributed to this literature by exploring whether collective leadership emerged organically following hospitals being placed into a networked structure. In this study, we have also highlighted the value of pairing network analysis with qualitative methods to interrogate network maps and illuminate the drivers of contact and 
JHOM 34,4

464

working relationships at different points. This has been highlighted in previous network research on leadership (Mehra et al., 2006) and is a key strength of this study. Whilst this cannot provide a comprehensive profile on what is happening and how and why individuals are interacting, it does enable insight into the collaborations and partnerships that are proving effective, and individuals' rationale for maintaining and building certain working partnerships.

It is important to note that the study also has its limitations. Firstly, it relied on selfreported ties and thus as with any research of this nature, was vulnerable to distortion. Social network methods are also dependent on a high response rate in order for the data to be considered reliable. Studies have explored the influence of missing data on network measures and found that network centrality measures were robust when sampling was above $80 \%$ (Costenbader and Valente, 2003). Degree was among the most robust of these, whereas betweenness does less well, especially when the sampling rate is below $70 \%$ of the network. Considering the lower response rate at the third time point, these results should be interpreted with caution.

Over the study period, the network experienced considerable growth and turnover, and consequently, the density of contact and collaborative relationships decreased. However, it may not necessarily be efficient, practical or feasible to have a high density of contact across a network as it may result in redundancy in the network. This is a topic of debate as it is argued that too much density may create excess or redundant communications. Granovetter (1983) reflected on the "strength of weak ties", where weak ties can play an important structural role in enhancing connectivity and facilitating the spread of novel information or phenomena, suggesting that strong ties and high density networks may not necessarily be optimal. In addition, it is recognised that teams or sub-groups may operate within networks of teams, where sub-teams may work towards specific goals while also working towards a global shared goal or vision (Sullivan et al., 2015). Future network studies of collective leadership may consider sub-groups as a unit of analysis in larger networks, or sub-groups that are expected to collaborate towards specific goals at various times.

\section{Practice implications}

There is strong evidence for the benefits of collective and system approaches to leadership. Based on this research, it is important to communicate a clear and consistent message about the plans for the organisations involved and be clear regarding the roles and expectations for those involved in introducing new approaches to leadership and integration. Honest collaboration, openness and certainty in communication will likely be important in order to help create the contextual conditions to enable collective and system approaches to introduce "stepping stones" to change, including developing interpersonal relationships between leaders, creating time and space for deep and shared reflection, and enhancing trust among colleagues.

\section{Note}

1. Contact could have included face-to-face discussions, phone calls, direct emails, etc.

\section{References}

Aime, F., Humphrey, S., Derue, D.S. and Paul, J.B. (2014), "The riddle of heterarchy: power transitions in cross-functional teams", Academy of Management Journal, Vol. 57, pp. 327-352. 
Al ramiah, A. and Hewstone, M. (2013), "Intergroup contact as a tool for reducing, resolving, and preventing intergroup conflict: evidence, limitations, and potential", American Psychologist, Vol. 68, p. 527.

Allport, G.W. (1954), The Nature of Prejudice, Addison-Wesley, Cambridge, MA.

Balkundi, P. and Kilduff, M. (2006), "The ties that lead: a social network approach to leadership", The Leadership Quarterly, Vol. 17, pp. 419-439.

Beirne, M. (2017), "The reforming appeal of distributed leadership", British Journal of Healthcare Management, Vol. 23, pp. 262-270.

Best, A., Greenhalgh, T., Lewis, S., Saul, J.E., Carroll, S. and Bitz, J. (2012), "Large-system transformation in health care: a realist review", The Milbank Quarterly, Vol. 90, pp. 421-456.

Borgatti, S.P., Everett, M.G. and Johnson, J.C. (2013), Analyzing Social Networks, SAGE Publications, London.

Borgatti, S.P., Mehra, A., Brass, D.J. and Labianca, G. (2009), "Network analysis in the social sciences", Science, Vol. 323, pp. 892-895.

Brass, D.J., Galaskiewicz, J., Greve, H.R. and Tsai, W. (2004), "Taking stock of networks and organizations: a multilevel perspective”, Academy of Management Journal, Vol. 47, pp. 795-817.

Braun, V. and Clarke, V. (2006), "Using thematic analysis in psychology", Qualitative Research in Psychology, Vol. 3, pp. 77-101.

Carter, D.R. and Dechurch, L.A. (2012), "Networks: the way forward for collectivistic leadership research", Industrial and Organizational Psychology, Vol. 5, pp. 412-415.

Carter, D.R., Dechurch, L.A., Braun, M.T. and Contractor, N.S. (2015), "Social network approaches to leadership: an integrative conceptual review", Journal of Applied Psychology, Vol. 100, p. 597.

Costenbader, E. and Valente, T.W. (2003), "The stability of centrality measures when networks are sampled", Social Networks, Vol. 25, pp. 283-307.

Cullen, K., Willburn, P., Chrobot-Mason, D. and Palus, C. (2014), Networks: How Collective Leadership Really Works, available at: https://www.ccl.org/wp-content/uploads/2015/04/networksHowColle ctive.pdf (accessed 26 October 2019).

D'innocenzo, L., Mathieu, J.E. and Kukenberger, M.R. (2014), "A meta-analysis of different forms of shared leadership-team performance relations", Journal of Management, Vol. 42 No. 7, pp. 1964-1991.

De brún, A., O’donovan, R. and Mcauliffe, E. (2019), "Interventions to develop collectivistic approaches to leadership in healthcare settings: a systematic review", BMC Health Services Research, Vol. 19, p. 72.

Denis, J.-L., Lamothe, L. and Langley, A. (2001), "The dynamics of collective leadership and strategic change in pluralistic organizations", Academy of Management Journal, Vol. 44, pp. 809-837.

Denis, J.L., Langley, A. and Cazale, L. (1996), "Leadership and strategic change under ambiguity", Organization Studies, Vol. 17, pp. 673-699.

Department of Health (2012), Future Health - A Strategic Framework for Reform of the Health Service 2012 - 2015, Department of Health, Dublin.

Dodgson, M. (1993), "Learning, trust, and technological collaboration”, Human Relations, Vol. 46, pp. 77-95.

Friedrich, T.L., Vessey, W.B., Schuelke, M.J., Ruark, G.A. and Mumford, M.D. (2009), “A framework for understanding collective leadership: the selective utilization of leader and team expertise within networks", The Leadership Quarterly, Vol. 20, pp. 933-958.

Granovetter, M. (1983), "The strength of weak ties: a network theory revisited”, Sociological Theory, pp. 201-233. 
JHOM 34,4

Greenhalgh, T., Humphrey, C., Hughes, J., Macfarlane, F., Butler, C. and Pawson, R. (2009), "How do you modernize a health service? A realist evaluation of whole-scale transformation in London", The Milbank Quarterly, Vol. 87, pp. 391-416.

Haslam, S.A., Oakes, P.J. and Turner, J.C. (1996), "Social identity, self-categorization, and the perceived homogeneity of ingroups and outgroups: the interaction between social motivation and cognition", in Sorrentino, R.M. and Higgins, E.T. (Eds), Handbook of motivation and cognition, Vol. 3. The interpersonal context, The Guilford Press, New York, pp. 182-222.

Higgins, J.R. (2013), The Establishment of Hospital Groups as a Transition to Independent Hospital Trusts [Online], Department of Health, Dublin, available at: http://health.gov.ie/wp-content/ uploads/2014/03/Full_Presentation.pdf (accessed 2 March 2017).

Hoppe, B. and Reinelt, C. (2010), "Social network analysis and the evaluation of leadership networks", The Leadership Quarterly, Vol. 21, pp. 600-619.

Jagosh, J., Macaulay, A.C., Pluye, P., Salsberg, J., Bush, P.L., Henderson, J., Sirett, E., Wong, G., Cargo, M. and Herbert, C.P. (2012), "Uncovering the benefits of participatory research: implications of a realist review for health research and practice", The Milbank Quarterly, Vol. 90, pp. 311-346.

Keyton, J., Ford, D.J. and Smith, F.L. (2008), "A mesolevel communicative model of collaboration", Communication Theory, Vol. 18, pp. 376-406.

Knight, L. (2002), "Network learning: exploring learning by interorganizational networks", Human Relations, Vol. 55, pp. 427-454.

Krackhardt, D. and Kilduff, M. (1999), "Whether close or far: social distance effects on perceived balance in friendship networks", Journal of Personality and Social Psychology, Vol. 76, p. 770 .

Kramer, M.W., Day, E.A., Nguyen, C., Hoelscher, C.S. and Cooper, O.D. (2018), "Leadership in an interorganizational collaboration: a qualitative study of a statewide interagency taskforce", Human Relations, Vol. 72 No. 2, pp. 397-419.

Laschinger, H.K.S., Finegan, J., Shamian, J. and Casier, S. (2000), "Organizational trust and empowerment in restructured healthcare settings: effects on staff nurse commitment", Journal of Nursing Administration, Vol. 30, pp. 413-425.

Mayo, M., Meindl, J.R. and Pastor, J.C. (2003), "Shared leadership in work teams: a social network approach", in Pearce, C.L. and Conger, J.A. (Eds), Shared Leadership - Reframing the Hows and Whys of Leadership, Sage Publications, Thousand Oaks, CA.

Mcauliffe, E. (2014), "Clinical governance in the Irish health system-a review of progress", Clinical Governance: An International Journal, Vol. 19, pp. 296-313.

Mehra, A., Smith, B.R., Dixon, A.L. and Robertson, B. (2006), "Distributed leadership in teams: the network of leadership perceptions and team performance", The Leadership Quarterly, Vol. 17, pp. 232-245.

Newell, S. and Swan, J. (2000), "Trust and inter-organizational networking”, Human Relations, Vol. 53, pp. 1287-1328.

Olson, C.A., Balmer, J.T. and Mejicano, G.C. (2011), "Factors contributing to successful interorganizational collaboration: the case of CS2day", Journal of Continuing Education in the Health Professions, Vol. 31 No. S1, pp. S3-S12.

Porter, M.E. and Lee, T.H. (2013), "The strategy that will fix health care”, Harvard Business Review, Vol. 91 No. 10, pp. 1-19.

Rycroft-Malone, J., Burton, C.R., Wilkinson, J., Harvey, G., Mccormack, B., Baker, R., Dopson, S., Graham, I.D., Staniszewska, S., Thompson, C., Ariss, S., Melville-Richards, L. and Williams, L. (2016), "Collective action for implementation: a realist evaluation of organisational collaboration in healthcare", Implementation Science, Vol. 11, p. 17.

Senge, P., Hamilton, H. and Kania, J. (2015), "The dawn of system leadership", Stanford Social Innovation Review, Vol. 13, pp. 27-33. 
Sullivan, S.D., Lungeanu, A., Dechurch, L.A. and Contractor, N.S. (2015), "Space, time, and the development of shared leadership networks in multiteam systems", Network Science, Vol. 3, pp. 124-155.

Suter, E., Oelke, N.D., Adair, C.E. and Armitage, G.D. (2009), "Ten key principles for successful health systems integration”, Healthcare Quarterly (Toronto, Ont.), Vol. 13, pp. 16-23.

Tajfel, H. and Turner, J.C. (2004), "The social identity theory of intergroup behaviour", in Jost, J.T. and Sidanius, J. (Eds), Key Readings in Social Psychology. Political Psychology: Key Readings, Psychology Press, New York, pp. 276-293, doi: 10.4324/9780203505984-16.

The King's Fund (2017), Leading across the Health and Care System: Lessons from Experience, The King's Fund, London.

Valente, T.W. (2010), Social Networks and Health: Models, Methods, and Applications, Oxford University Press, Oxford.

Wang, D., Waldman, D.A. and Zhang, Z. (2014), "A meta-analysis of shared leadership and team effectiveness", Journal of Applied Psychology, Vol. 99, p. 181.

West, E., Barron, D.N., Dowsett, J. and Newton, J.N. (1999), "Hierarchies and cliques in the social networks of health care professionals: implications for the design of dissemination strategies", Social Science and Medicine, Vol. 48, pp. 633-646.

West, M., Armit, K., Loewenthal, L., Eckert, R., West, T. and Lee, A. (2015), Leadership and Leadership Development in Healthcare: The Evidence Base, The Kings Fund, London.

West, M., Eckert, R., Steward, K. and Pasmore, B. (2014), Developing Collective Leadership for Health Care, The King's Fund, London.

World Health Organization (2000), "The world health report 2000, Health systems:improving performance [online]", Geneva, available at: http://www.who.int/whr/2000/en/whr00_en.pdf (accessed 8 December 2017).

World Health Organization (2008), "Integrated health services - what and why?", in WHO (Ed.), Technical Brief No. 1, Geneva.

\section{Corresponding author}

Aoife De Brún can be contacted at: aoife.debrun@ucd.ie

For instructions on how to order reprints of this article, please visit our website:

www.emeraldgrouppublishing.com/licensing/reprints.htm

Or contact us for further details: permissions@emeraldinsight.com 